\title{
Revisão integrativa sobre redes de cuidados aos adolescentes em situação de violência sexual
}

\author{
An integrative review of care networks for adolescents \\ who have experienced sexual violence
}

Gabrielly Becalli Broseguini (https://orcid.org/0000-0002-2812-7463) ${ }^{1}$

Alexandra Iglesias (https://orcid.org/0000-0001-7188-9650) ${ }^{2}$

${ }^{1}$ Universidade Federal do Espírito Santo (UFES). Av. Fernando Ferrari 514, Goiabeiras. 29075910 Vitória ES Brasil. gabriellybeccalli@gmail.com ${ }^{2}$ Departamento de Psicologia, UFES. Vitória ES Brasil.

\begin{abstract}
Interventions aimed at children and adolescents who have suffered sexual violence should be coordinated across different services and include a range of actors if they are to ensure comprehensive, interdisciplinary and continuous care. Sexual violence against adolescents involves specific issues, such as the risk of pregnancy, abortion, the right to emergency contraception, and the difficulty some people have in discerning between violence and consent. The objective of this study was to identify and analyze national literature on care networks for adolescents who have experienced sexual violence. We conducted an integrative literature review, performing a content analysis of 11 articles focusing on the following five thematic categories: concepts of networks, network-based care services, network-based care practices, difficulties in implementing network-based care, and proposals for network-based care. Few of the analyzed articles presented a definition of care networks or described how they work. The findings show that literature focusing specifically on care networks for adolescents who have experienced sexual violence is scarce. Finally, it was noted that few articles discussed the role of the family, health regions and other potentially important actors in care networks. Key words Sexual Violence, Adolescent, Care Network, Integrative Review
\end{abstract}

Resumo A intervenção na área da violência sexual na infância e adolescência requer articulação entre vários serviços e atores para a garantia do cuidado integral, interdisciplinar e continuado. No caso dos adolescentes, há particularidades nessa questão, como: a possibilidade de uma gestação e de sua interrupção legal; o direito à anticoncepção de emergência; e certa dificuldade, por parte de muitos atores sociais, de discernimento entre violência e consentimento. Objetivou-se levantare analisar as produções científicas nacionais sobre as redes de cuidados aos adolescentes em situação de violência sexual. Para tanto, utilizou-se da revisão integrativa de literatura, sendo selecionados 11 artigos, submetidos a análise de conteúdo temática. Destacaram-se nos resultados cinco categorias: concepções de rede, serviços disponiveis para o cuidado em rede, práticas para o cuidado em rede, dificuldades da atuação em rede e propostas para o cuidado em rede. Poucos dos artigos analisados trazem o entendimento de redes de cuidados e o modo como elas funcionam. Observou-se ainda desfalque de produções que lidem mais especificamente com a questão da adolescência nesses casos. Além disso, notou-se que poucos artigos abordam a família e o território como componentes possíveis na constituição dessa rede.

Palavras-chave Violência Sexual, Adolescente, Redes de Cuidados, Revisão Integrativa 


\section{Introdução}

A violência sexual configura-se como problema de saúde pública, principalmente por sua repercussão física e psicossocial, como doenças sexualmente transmissíveis, distúrbios psicológicos e psiquiátricos, comportamentos de medo, insegurança, vergonha, ideação suicida, dificuldades no estabelecimento de relações afetivas, engajamento em exploração sexual (prostituição), dependência de substâncias psicoativas, dentre outros impactos ${ }^{1,2}$.

De acordo com a biblioteca virtual em saúde (BVS), a violência sexual, como um descritor em ciências da saúde (DeSC), refere-se a um abuso de poder, no qual um indivíduo é usado para gratificação sexual de outro, por meio da indução a práticas sexuais, com ou sem violência física. No que se refere mais especificamente à criança e ao adolescente, essa situação se agrava pela restrição, desse público, de "condições maturacionais e psicobiológicas de enfrentamento, transgredindo assim, as normas sociais, morais e legais"3 (p.467), como o direito à liberdade, autonomia e exercício responsável da sexualidade.

Segundo o Ministério da Saúde (MS) ${ }^{4}$, a violência sexual infantojuvenil configura-se como todo ato, de qualquer natureza, de cunho homossexual ou heterossexual, em que o agressor - familiar ou estranho -, em estágio psicossexual mais avançado que a criança ou adolescente, utiliza-se sexualmente da vítima para seu prazer sexual, por meio do aliciamento, violência física ou ameaça, podendo haver ou não contato físico. Para Habigzang et al. ${ }^{3}$, o abuso pode acontecer tanto contra a vontade da criança ou do adolescente, como "pela indução de sua vontade, através das relações de poder e confiança entre a vítima e $\mathrm{o}$ agressor, bem como, pelo uso de violência física ou psicológica (ameaças e barganhas)"3(p.467).

De acordo com dados do Portal Brasil, em 2015 e 2016, 37 mil denúncias de violência sexual na faixa etária de zero a 18 anos foram recebidas pelo "Disque Direitos Humanos - Disque 100", canal de comunicação da Ouvidoria Nacional dos Direitos Humanos. Apesar do número expressivo, estima-se que os dados epidemiológicos desses casos sejam subdimensionados, considerando também, o preconceito, o tabu e o silêncio envoltos aos casos de crimes sexuais ${ }^{5}$.

No caso dos adolescentes há, por vezes, a acusação da vítima, aliada ao que parece uma dificuldade de discernimento entre violência e consentimento. Nas situações retratadas pela pesquisa de De Antoni et al. ${ }^{6}$, mães de adoles- centes banalizaram ou naturalizaram a violência sofrida pelas filhas. Esse discurso pode englobar, inclusive, profissionais de saúde, como bem coloca Trabbold et al. ${ }^{7}$. Dessa maneira, o seguinte questionamento é levantado: "estariam dessa forma os adultos sem medidas para avaliar o que se constitui ou não uma violência sexual em relação à sexualidade vivida pelos jovens ou adolescentes?"7(p.81).

Nesse contexto, o presente trabalho optou por focar o fenômeno da violência sexual ao adolescente, devido às particularidades que envolvem o adolescente nessa situação, como a possibilidade de uma gestação e mesmo de sua interrupção legal, assim como o direito à anticoncepção de emergência. Somado a isso, é notória a restrição de estudos direcionados especificamente ao adolescente em situação de violência sexual. Segundo Deslandes et al. ${ }^{8}$, foi realizado um levantamento em janeiro de 2015, na base SciELO, tendo a violência sexual como assunto e incluindo o descritor "atenção". Como resultado, 13 artigos foram encontrados. Diferentemente, quando refinada a busca para adolescentes, apenas três trabalhos permaneceram.

Em se tratando da temática da adolescência, o Estatuto da Criança e do Adolescente (ECA), lei $n^{\circ} 8.069$ de 13 de julho de 1990, considera adolescente a pessoa entre 12 e 18 anos incompletos. Vale destacar que esse estatuto é marco na proteção dos direitos das crianças e adolescentes no Brasil e aborda a importância da proteção integral pela tríade Estado, sociedade e família. No mais, tal documento traz uma concepção a respeito dessas crianças e adolescentes não mais como objetos de tutela, mas como sujeitos de direito, que devem ser salvos de toda forma de violência9.

A adolescência refere-se a uma construção única para cada sujeito, marcada por inúmeras descobertas e transformações, que ocorrem de forma evidente no próprio corpo do adolescente, assim como na sua vida social e afetiva ${ }^{10,11}$.

Rassial ${ }^{12}$ define a adolescência como um momento em que o sujeito se depara com uma reapropriação de uma imagem de corpo transformada, "possuindo sua própria lógica nos processos de identificação" ${ }^{12}$ (p.12). Lo Bianco e Nicacio ${ }^{13}$ caracterizam a historicidade do que atualmente se entende por adolescência, destacando que tal denominação surgiu com o advento da sociedade burguesa. Em algumas sociedades, por exemplo, a passagem da infância para a vida adulta era marcada por ritos, como mutilações ${ }^{13}$. Esse corte efetivo realizado por esses rituais deram lugar, 
na modernidade, a uma prolongada preparação, em que os ditos adolescentes são lançados "numa condição marcada pela ambiguidade e pela incerteza"13(p.79), pois os limites entre infância e adultez não mais são claros e simbolicamente demarcados.

No mais, Menandro et al. ${ }^{14}$ identificaram associações de conteúdos negativos referentes aos adolescentes nos meios de comunicação, pautadas em representações de rebeldia, dependência e imaturidade. De acordo com as autoras, o discurso profissional e oficial se dirige, cada vez mais, a prescrições direcionadas à prevenção de comportamentos de risco dos jovens, o que ressalta ainda mais esse caráter da imaturidade. Assim, é evidente o discurso social do adolescente como aquele que deve ser controlado e disciplinado, ao invés, muitas vezes, de uma perspectiva de cuidado $^{14}$

Ao considerar todas essas especificidades da adolescência e a temática da violência sexual, fazse pertinente questionar: como exatamente esses adolescentes em situação de violência sexual têm sido cuidados?

Com o objetivo de afirmar estratégias de ações governamentais e não governamentais, o Ministério da Justiça/Secretaria de Estado dos Direitos Humanos instituiu, em 2000, o Plano Nacional de Enfrentamento da Violência Sexual Contra Crianças e Adolescentes ${ }^{4}$. Trata-se de um documento voltado a assegurar um instrumento legítimo de garantia de direitos e defesa de crianças e adolescentes, por meio do fornecimento de diretrizes para a viabilização da política de atendimento estabelecida pelo ECA, envolvendo uma rede de serviços ${ }^{15}$.

Nesse sentido, aponta-se a necessidade de articulação entre vários serviços, atores e setores para a garantia do direito de um cuidado integral, considerando a complexidade da situação em questão. Santos e Ippolito ${ }^{16}$ explicam que, no cuidado de crianças e adolescentes, a rede potencializa uma ação mais abrangente e multidisciplinar de diferentes profissionais, em diversas instituições. As redes seriam um sistema que busca aprofundar e estabelecer padrões estáveis de interrelações ${ }^{17}$. Para Castells ${ }^{17}$, as redes são novas formas de organização social, do Estado ou da sociedade baseadas na cooperação, na inexistência de hierarquia, no compartilhamento de objetivos comuns, na confiança, na interdependência e intercâmbio constante e duradouro entre unidades dotadas de autonomia.

Em outras palavras, afirma-se que a intervenção na área da violência sexual contra a criança e adolescente requer um cuidado interdisciplinar, especializado, continuado e articulado, promovido por um conjunto de atores sociais atuantes de modo coordenado ${ }^{18-20}$.

Nessa discussão, alguns estudos destacam o quanto esse trabalho pode ser deficitário e, muitas vezes, acabar exigindo que histórias tão delicadas e íntimas sejam recontadas em diferentes ambientes. Gava e Dell'aglio ${ }^{21}$ falam da "via-sacra" que as pessoas comumente realizam ao perpassarem por diferentes serviços. Isso pode apontar para a pouca articulação entre as instituições, que se limitam a lógica do encaminhamento, em um movimento de transferência de responsabilidade e não propriamente um compartilhamento de responsabilidades e de trocas de informações entre os serviços. Certamente essas parcerias poderiam evitar que a pessoa fragilizada tenha que contar a cada instituição toda a sua história.

Nesse contexto, pretende-se por meio deste estudo levantar e analisar as produções científicas nacionais sobre as redes de cuidados aos adolescentes em situação de violência sexual, destacando nesses trabalhos, as concepções de rede, os serviços disponíveis para esse cuidado, as práticas de cuidado em rede, as dificuldades dessa atuação e as possíveis propostas para o cuidado em rede.

\section{Método}

Trata-se de um estudo de revisão integrativa de literatura acerca das redes de cuidados aos adolescentes em situação de violência sexual. O interesse por essa temática surgiu da vivência profissional da pesquisadora de certa dificuldade em articular essas redes para a efetivação do cuidado aos adolescentes. Assim, optou-se pela revisão integrativa por ser um recurso importante de sistematização das produções científicas sobre o assunto, além de apontar possíveis lacunas do conhecimento que precisam ser preenchidas com a realização de novos estudos, podendo auxiliar profissionais e pesquisadores no cotidiano de trabalho ${ }^{22-24}$.

Assim, seguiu-se com as etapas da revisão integrativa para a constituição desse estudo: seleção das questões de pesquisa, elaboração dos descritores, definição dos critérios de inclusão e exclusão dos artigos, categorização dos estudos, análise dos estudos selecionados para a síntese do conhecimento sobre o assunto em questão ${ }^{22-24}$.

Foram questões norteadoras desse estudo: quais articulações da rede têm se configurado para o cuidado aos adolescentes em situação de violência sexual? Quais as concepções de rede 
nesse cuidado? Quais as potencialidades e dificuldades enfrentadas para a efetivação desse trabalho em rede? Quais as experiências existentes no país, dessas redes, podem ser parâmetros para construção de novas políticas públicas e de práticas efetivas de cuidado?

A partir daí, no período de março a maio de 2017, foi feita a busca dos artigos científicos nacionais sobre o tema nas bases de dados: Portal de Periódicos Capes, SciELO e LILACS. Os descritores utilizados foram "adolescente", "adolescência", "abuso sexual", "violência sexual", "assistência integral à saúde", "integralidade em saúde", "saúde do adolescente", "serviços de saúde", "assistência à saúde" e "rede". Esses descritores foram organizados para a busca em trio, a fim de englobarem as temáticas principais desse levantamento: adolescente, violência sexual e rede.

É importante esclarecer que o uso das duas terminologias na busca, "abuso sexual" e "violência sexual", segue apontamento da literatura. $\mathrm{Na}$ definição dos DeCS, o descritor "abuso sexual" aparece como sinônimo de "violência sexual". Enquanto que o descritor "exploração sexual"sequer foi encontrado. Por outro lado, publicações de referência consideram a denominação "violência sexual" ampla, abordando tanto o abuso sexual, quanto a exploração sexual.

Não há consenso quanto às definições das terminologias. Assim, mesmo clara a importância da diferenciação para fins legais, optou-se neste estudo por trabalhar com a designação violência sexual de forma ampliada, seguindo a linha dos DeSC, não enfocando as especificidades das questões de exploração sexual ou de tráfico de pessoas.

Foram incluídos os artigos científicos disponíveis online na íntegra e em idioma português (a fim de conhecer especificamente a realidade brasileira), publicados no período de 2007 a 2017, que relacionavam em seus objetivos o cuidado em rede aos adolescentes em situação de violência sexual. A partir de tais critérios, foi feita a checagem dos títulos e dos resumos, para que fossem detectados os trabalhos que tratavam especificamente das redes de cuidados aos adolescentes em situação de violência sexual. Destaca-se que, embora o público adolescente tenha sido focado na busca, os artigos encontrados não enfocaram a questão na adolescência, por isso incluiram-se os estudos que tratavam da criança e adolescente em conjunto. No mais, apesar do período estabelecido ser de 2007 à 2017, foram encontrados apenas trabalhos de 2010 à 2016.

Foram excluídos: teses, dissertações, trabalhos de conclusão de curso, capítulos de livro, artigos que não apresentavam textos completos em português, artigos que discutiam a questão da violência sexual contra adolescentes, mas não abordavam as redes de cuidados, artigos que abordavam a violência sexual a outro público que não incluíam adolescentes e artigos que tratavam unicamente da exploração sexual contra adolescentes.

A partir das palavras-chave foram identificados 2.166 artigos: 746 pelo Portal de Periódicos Capes, 97 pelo SciELO e 1.323 pelo LILACS. Após aplicação dos critérios de inclusão e exclusão e de descartar textos repetidos, restaram 25 artigos. Desses 25 artigos, após leitura na íntegra e passagem pelo crivo de dois pesquisadores, 11 foram os trabalhos selecionados para análise. Somente esses 11 artigos traziam em seus objetivos a questão das redes de cuidados aos adolescentes em situação de violência sexual.

Seguiu-se, então, com a aplicação de técnica de Análise de Conteúdo ${ }^{25}$ Temática, que consistiu na (1) leitura flutuante dos artigos selecionados, com fichamento do material em tabela composta dos objetivos e principais resultados, (2) seleção das unidades de análise orientada pelas questões de pesquisa e (3) categorização. Esse processo resultou em cinco categorias: concepções de rede, serviços disponíveis para o cuidado em rede, práticas para o cuidado em rede, dificuldades da atuação em rede e propostas para o cuidado em rede.

\section{Resultados}

Os artigos selecionados foram organizados aqui em um quadro explicativo (Quadro 1), contendo autoria/ano de publicação, título, periódico publicado e objetivo.

\section{Concepções de rede}

Esta categoria apresenta os entendimentos de rede. Cinco dos trabalhos não enfocam uma definição para a terminologia rede ou suas derivações ("rede de serviçoos" "rede de atendimento", "rede de proteção", entre outras), pautando-se basicamente em sua composição ao descrevê $-1 a^{8,15,26-28}$. Assim colocam Deslandes et al. ${ }^{8}$, que para $o$ atendimento às crianças e adolescentes, $o$ município dispõe de um sistema de rede de instâncias nos setores de Justiça, Saúde, Educação, Desenvolvimento Social.

Por outro lado, os outros seis i-3,16,18,19 $^{-1}$ artigos descrevem a conceituação de rede. Faraj e Siquei$\mathrm{ra}^{19}$ deliberam que as redes são "processos dinâ- 
Quadro 1. Caracterização dos artigos selecionados para a revisão integrativa do período de 2007 a 2017.

\begin{tabular}{|c|c|c|c|c|}
\hline Item & $\begin{array}{l}\text { Autor } \\
\text { (Ano) }\end{array}$ & Título & Periódico & Objetivo \\
\hline 1 & $\begin{array}{l}\text { Paixão e } \\
\text { Deslandes } \\
(2010)^{28}\end{array}$ & $\begin{array}{l}\text { Análise das Políticas Públicas } \\
\text { de Enfrentamentoda Violência } \\
\text { Sexual Infantojuvenil }\end{array}$ & $\begin{array}{l}\text { Saúde e } \\
\text { Sociedade }\end{array}$ & $\begin{array}{l}\text { Analisar a principal política pública brasileira para } \\
\text { o enfrentamento da violência sexual infantojuvenil } \\
\text { no Brasil sob o enfoque doseu eixo de atendimento, } \\
\text { denominado "garantia de atendimento integral e } \\
\text { especializado". }\end{array}$ \\
\hline 2 & $\begin{array}{l}\text { Costa et al. } \\
(2010)^{26}\end{array}$ & $\begin{array}{l}\text { Avaliação do Programa } \\
\text { Nacional de Ações Integradas } \\
\text { e Referenciais (PAIR) para o } \\
\text { enfrentamento da violência } \\
\text { sexual contra crianças e } \\
\text { adolescentes, em Feira de } \\
\text { Santana, Bahia. }\end{array}$ & $\begin{array}{l}\text { Ciência } \\
\text { e Saúde } \\
\text { Coletiva }\end{array}$ & $\begin{array}{l}\text { Apresentar a avaliação das ações do PAIR implementadas } \\
\text { em Feira de Santana, quanto à articulação política } \\
\text { e institucional, fortalecimento e atuação da rede de } \\
\text { atendimento às vítimas de violência, no período de } 2003 \\
\text { a } 2006 \text {. }\end{array}$ \\
\hline 3 & $\begin{array}{l}\text { Habigzang } \\
\text { et al. } \\
(2011)^{3}\end{array}$ & $\begin{array}{l}\text { A Revelação de Abuso Sexual: } \\
\text { As Medidas Adotadas pela } \\
\text { Rede de Apoio }\end{array}$ & $\begin{array}{l}\text { Psicologia } \\
\text { Teoria e } \\
\text { Pesquisa }\end{array}$ & $\begin{array}{l}\text { Identificar e analisar as medidas adotadas pela rede de } \\
\text { apoio de crianças e adolescentes após a revelação de } \\
\text { abuso sexual. }\end{array}$ \\
\hline 4 & $\begin{array}{l}\text { Paixão e } \\
\text { Deslandes } \\
(2011)^{15}\end{array}$ & $\begin{array}{l}\text { Abuso Sexual } \\
\text { InfantoJuvenil:ações } \\
\text { municipais da Saúde para a } \\
\text { garantia do atendimento } \\
\end{array}$ & $\begin{array}{l}\text { Ciência } \\
\text { e Saúde } \\
\text { Coletiva }\end{array}$ & $\begin{array}{l}\text { Analisar as ações da Secretaria Municipal de Saúde } \\
\text { e Defesa Civil do Rio de Janeiro para garantir o } \\
\text { atendimento à população infantojuvenil vítima } \\
\text { deviolência sexual. }\end{array}$ \\
\hline 5 & $\begin{array}{l}\text { Rodrigues } \\
\text { et al. } \\
(2011)^{18}\end{array}$ & $\begin{array}{l}\text { Rede contra Violência Sexual } \\
\text { no DF: umarepresentatividade } \\
\text { da saúde e da educação } \\
\text { naadolescência } \\
\end{array}$ & $\begin{array}{l}\text { Comunicação } \\
\text { em Ciências } \\
\text { da Saúde. }\end{array}$ & $\begin{array}{l}\text { Destacar a necessidade da efetivação de políticas públicas } \\
\text { quevisem à reestruturação da rede contra a violência, } \\
\text { com foco na saúde e na educação. }\end{array}$ \\
\hline 6 & $\begin{array}{l}\text { Santos et } \\
\text { al. }(2011)^{29}\end{array}$ & $\begin{array}{l}\text { As medidas protetivas na } \\
\text { perspectiva de famílias em } \\
\text { situação de violência sexual }\end{array}$ & Psico & $\begin{array}{l}\text { Conhecer os significados construídos e conferidos pelas } \\
\text { famílias em situação de violência sexual contra suas } \\
\text { crianças e/ou adolescentes às medidas protetivas, durante } \\
\text { seu percurso na rede de atendimento legal, social e de } \\
\text { saúde, entre outros, desde o momento da denúncia } \\
\text { formal. }\end{array}$ \\
\hline 7 & $\begin{array}{l}\text { Kappel et } \\
\text { al. }(2012)^{1}\end{array}$ & $\begin{array}{l}\text { Enfrentamento da violência } \\
\text { sexual infanto-juvenil na } \\
\text { perspectiva dos participantes } \\
\text { de um curso de formação }\end{array}$ & $\begin{array}{l}\text { Cogitare } \\
\text { Enfermagem }\end{array}$ & $\begin{array}{l}\text { Identificar as dificuldades, pessoas e/ou instituições } \\
\text { envolvidas e estratégias de enfrentamento da violência na } \\
\text { perspectiva de } 57 \text { participantes do Curso de Formação } \\
\text { do Programa de Ações Integradas e Referenciais de } \\
\text { Enfrentamento à Violência Sexual Infanto-juvenil } \\
\end{array}$ \\
\hline 8 & $\begin{array}{l}\text { Faraj e } \\
\text { Siqueira } \\
(2012)^{19}\end{array}$ & $\begin{array}{l}\text { Atendimento e a rede } \\
\text { de proteção da criança } \\
\text { e do adolescente vítima } \\
\text { de violência sexual na } \\
\text { perspectiva dos profissionais } \\
\text { do CREAS }\end{array}$ & Barbarói & $\begin{array}{l}\text { Conhecer a percepção dos profissionais que realizam a } \\
\text { avaliação e o atendimento da criança e do adolescente } \\
\text { vítima de violência sexual em um CREAS quanto ao } \\
\text { atendimento realizado pelo serviço e a Rede de Proteção } \\
\text { da criança e do adolescente no município }\end{array}$ \\
\hline 9 & $\begin{array}{l}\text { Espindola } \\
\text { e Batista } \\
(2013)^{27}\end{array}$ & $\begin{array}{l}\text { Abuso SexualInfanto-Juvenil: } \\
\text { A Atuação doPrograma } \\
\text { Sentinelana Cidade } \\
\text { deBlumenau/SC }\end{array}$ & $\begin{array}{l}\text { Psicologia: } \\
\text { Ciência e } \\
\text { Profissão }\end{array}$ & $\begin{array}{l}\text { Identificar a atuação do Programa Sentinela, da cidade de } \\
\text { Blumenau/SC, diante da violência sexual infanto-juvenil } \\
\text { e mapear seus fatores de assistência e de vulnerabilidade. }\end{array}$ \\
\hline 10 & $\begin{array}{l}\text { Deslandes } \\
\text { e Campos } \\
(2015)^{2}\end{array}$ & $\begin{array}{l}\text { A ótica dos conselheiros } \\
\text { tutelares sobre a ação da } \\
\text { rede para a garantia da } \\
\text { proteção integral a crianças } \\
\text { e adolescentesem situação de } \\
\text { violência sexual }\end{array}$ & $\begin{array}{l}\text { Ciência } \\
\text { e Saúde } \\
\text { Coletiva }\end{array}$ & $\begin{array}{l}\text { Conhecer a ótica dos conselheiros tutelares sobre as } \\
\text { principais dificuldades de atuação e mobilização da } \\
\text { rede para garantir a proteção integral de crianças e } \\
\text { adolescentes em situação de abuso e exploração sexual no } \\
\text { município do Rio de Janeiro. }\end{array}$ \\
\hline 11 & $\begin{array}{l}\text { Deslandes } \\
\text { et al. } \\
(2016)^{8}\end{array}$ & $\begin{array}{l}\text { Atendimento à saúde de } \\
\text { crianças e adolescentes em } \\
\text { situação de violência sexual, } \\
\text { em quatro capitais brasileiras }\end{array}$ & $\begin{array}{l}\text { Interface } \\
\text { (Botucatu) }\end{array}$ & $\begin{array}{l}\text { Analisar a atenção à saúde de crianças e adolescentes } \\
\text { em situação de violência sexual (VS) na rede pública } \\
\text { municipal de saúde de quatro capitais brasileiras - Porto } \\
\text { Alegre (RS), Belém (PA), Fortaleza (CE) e Campo } \\
\text { Grande (MS). }\end{array}$ \\
\hline
\end{tabular}


micos, em movimento e conflito a fim de realizar intervenções em conjunto para uma maior eficácia" $^{19}$ (p.77). O ponto de partida do artigo de Deslandes e Campos foi o conceito de rede social, entendido como "tecidos sociais que se articulam em torno de objetivos e focos de ação comuns, cuja teia é construída num processo de participação coletiva e de responsabilidades compartilhadas" 2 (p.2175). Ao encontro da ideia de ações compartilhadas, tem-se que a rede de atenção "implica em relações horizontais, onde todos os âmbitos se responsabilizam"18(p.345).

Comparece também a definição de rede de apoio social e afetiva, que ressalta a família em sua composição: "conjunto de sistemas e de pessoas significativas (estrutura) que compõem os relacionamentos existentes e percebidos pela criança"3(p.468). Além disso, Santos et al..$^{16}$ dizem de uma rede institucional como alternativa de organização, que possibilite garantir flexibilidade, conectividade e efetividade das ações desenvolvidas por cada instância.

\section{Serviços disponíveis para o cuidado em rede}

Essa categoria aponta os serviços identificados pelos artigos como componentes das redes de cuidados aos adolescentes em situação de violência sexual. Dos 11 artigos analisados, oito ${ }^{1-}$ $3,8,19,26,27,29$ apresentam os serviços componentes de rede. Destacaram como instituições parceiras nesse cuidado aquelas relacionadas à educação, saúde, assistência social ${ }^{1,3,26}$ e os serviços ligados à rede de defesa dos direitos, como o Conselho Tutelar ${ }^{1,3,8,19,26,29}$. Foram citados também: a promotoria ${ }^{2,3}$, Delegacias da Criança e do Adolescente $^{2,8,19}$, juizado da infância e juventude ${ }^{3,19}$, Defensoria Pública e Conselho Municipal dos Direitos da Criança e do Adolescente ${ }^{1}$. Habigzang et al. ${ }^{3}$ agregam a essa possível rede a família.

Nomearam-se dentro dos serviços da assistência o CRAS e CREAS",8,26,29 e da saúde o "hospital público onde se desenvolve um projeto de atendimento às vítimas de violência intrafamiliar para atendimento psicoterapêutico"29(p.81).

Mencionaram também serviços nacionais: unidades de saúde ${ }^{8,27}$ e CAPSi ${ }^{27}$, além de algumas instituições regionais, como, o "projeto não governamental Vira Vida, a Rede Aquarela, da Secretaria Municipal de Direitos Humanos"s(p.870) e a "ONG Núcleo de Atenção a Criança e Adolescente"2(p.2177).

Deslandes et al. ${ }^{8}$ apontam na composição da rede em Belém, o hospital da Santa Casa de Misericórdia e o posto do Instituto Médico Legal; já em Porto Alegre tem-se: o Centro de Referência de Atendimento Infantojuvenil, do Hospital Materno-Infantil Presidente Vargas. "Em Campo Grande, foi referido que, além do CAPSi, havia um Centro de Atenção Psicossocial Pós-Trauma, que era um dos únicos do País especializado no atendimento de transtornos e traumas decorrentes da vivência de violências" "(p.870). Enquanto em Fortaleza foi citado o "Centro de Referência de Direitos Humanos de Crianças e Adolescentes, que monitora as denúncias do Disque 100 e dos Conselhos Tutelares"8(p.870).

\section{Práticas para o cuidado em rede}

Os únicos dois $\operatorname{artigos}^{18,19}$ que descrevem as práticas adotadas para o trabalho em rede, falam do acolhimento, tratado como um momento de coleta e análise de dados e direcionado também para a definição do tratamento desse adolescente e de sua família, ou seja, os encaminhamentos a serem feitos. "Vê se há a necessidade de encaminhar para exames, se para um clínico, se para um ginecologista e, também, do psicólogo e do serviço social” ${ }^{\prime 18}$ (p.350). No caso do CREAS é realizado um plano de atendimento, elaborado de forma conjunta entre psicólogos e assistentes sociais ${ }^{19}$. Em seguida "é enviado relatório para Conselhos Tutelares, Delegacias ou para o órgão que encaminhou o caso ao CREAS. Encaminha-se também o relatório para o Fórum da Comarca da cidade no caso de haver processo em trâmite"19(p.76).

\section{Dificuldades da atuação em rede}

Essa categoria apresenta as dificuldades para a efetivação do trabalho em rede no cuidado à criança e adolescente em situação de violência sexual. Sete ${ }^{1-3,18,19,28,29}$ artigos analisados apresentam essas dificuldades no cuidado em rede a esse público. Uma das principais dificuldades apontada refere-se à falta de comunicação entre os serviços, atores e setores dessa rede ${ }^{2,3,19}$. Nas palavras de Faraj e Siqueira ${ }^{19}$ não se consegue "manter uma comunicação adequada entre instituições, órgãos e atores, até mesmo com os serviços especializados da Rede (CAPS, Ambulatório de Saúde Mental, etc. ${ }^{\prime \prime 19}(p .77)$. Ainda de acordo com os autores, "não se consegue trabalhar no sistema de referência e contra-referência" ${ }^{19}(p .78)$ entre os próprios serviços da assistência - CRAS e CREAS, "não se consegue encaminhar"19(p.78), "falta informatização do Serviço e da Rede"19(p.79).

Por outro lado, Santos et al. ${ }^{29}$ apontam como dificuldade a restrição dos procedimentos, "a 
encaminhamentos para outras instituições, o que pode gerar a falsa ideia de resolução dos $\operatorname{casos}^{29}(\mathrm{p} .84)$. Os autores argumentam que tal procedimento gera "repetições de intervenções e avaliações e a super-exposição da família, promovendo o seu esgotamento e esgotando as possibilidades de resultados"29(p.85). Nesse sentido, alguns artigos destacam a falta de compartilhamento de informações sobre os atendimentos feitos e de suas necessidades ${ }^{1,2,28}$, a "falta planejamento coordenado de diferentes serviços que compõem a rede"3(p.472), a falta de clareza do 'trabalho em rede', a falta de padronização de conduta $^{28}$ e a "inexistência de uma definição transparente acerca do papel desempenhado pelos agentes institucionais dentro da rede"1(p.221).

Apontaram ainda como dificuldade a insuficiência de instituições para atendimento especializado e de articulação interinstitucionais ${ }^{18}$. Nesse contexto, Paixão e Deslandes ${ }^{28}$ discorrem sobre a "dificuldade de articulação entre os diversos órgãos de atendimento, inclusive com desconhecimento por parte da rede de enfrentamento sobre o fluxo de encaminhamento dos usuários para as diversas áreas de interesse"28(p.121). Para as autoras são "poucas as opções de encaminhamento das vítimas para as redes de serviço, assim como nestas não há prioridade para o atendimento de abuso e exploração sexual" ${ }^{28}$ (p.121).

Seguindo nas dificuldades, os artigos referem a morosidade no atendimento ${ }^{18}$ e o reduzido número de profissionais que atuam nas organizações e nos serviços para atenderem melhor essa demanda ${ }^{18,28}$. Deslandes e Campos ${ }^{2}$ apontam como dificultador o volume expressivo de demandas, que obstaculizam uma articulação em rede para todos os casos, bem como "a insuficiência de políticas socioassistenciais e educacionais"2(p.2177). Assim, Paixão e Deslandes ${ }^{28}$ apontam para uma falta de apoio das políticas públicas. Enquanto Rodrigues et al. ${ }^{18}$ e Kappel et al. ${ }^{1}$ falam de uma carência e escassez de políticas públicas de modo geral.

Descreveram também como dificuldades para o cuidado em rede as crianças e adolescentes em situação de violência sexual, a falta de capacitação continuada, de participação $\operatorname{popular}^{28}$ e o despreparo dos profissionais para atendimento a esse tipo de demanda ${ }^{1,2}$. Nas palavras de Paixão e Deslandes ${ }^{28}$ há "pouca clareza no que tange o acompanhamento das vítimas, demonstrando uma falta de sistematização dos procedimentos e evidenciando a carência de monitoramento e supervisão técnica dos governos estaduais, municipais e federal"28(p.122).

\section{Propostas para o cuidado em rede}

Nessa categoria serão apresentadas as propostas presentes nos artigos para a efetivação do cuidado em rede as crianças e adolescentes em situação de violência sexual. Oito ${ }^{1-3,8,18,19,26,28}$ artigos selecionados destacam propostas para o fortalecimento desse cuidado em rede. Entre os artigos a maioria destacou a necessidade de capacitação para os profissionais trabalharem em rede de cuidado a esse público ${ }^{1-3,18,26}$. Como descrito por Habigzang et al. " "capacitação contínua e avaliação dos programas de capacitação utilizados para identificação de possíveis falhas"3(p.472) nessas articulações em rede.

Fez-se presente também a necessidade de fortalecimento da rede de proteção ${ }^{1,26}$ e das instituições ${ }^{1,26}$, com investimento governamental e social $^{26}$ e com a incorporação de ações estratégicas nos planos do governo ${ }^{2}$.

Os autores também destacam o compartilhamento do propósito de trabalho em rede "por todos os atores e instituições mobilizadas, não bastando apenas a vontade e determinação política para garantir a mudança de paradigma das políticas sociais"28(p.121). Nessa linha de raciocínio, Deslandes e Campos ${ }^{2}$ anunciam a imprescindibilidade da "consolidação de fluxos planejados e pactuados de ação entre os distintos serviços e atores"2(p.2180) que compõem essa possível rede. Ou ainda a "consolidação de uma agenda comum para universalizar um modelo eficiente de atendimento intersetorial" 28 (p.124).

Faraj e Siqueira ${ }^{19}$ apontam para a "necessidade do trabalho de conscientização dos atores envolvidos, promovendo a referência e a contra -referência, além de reuniões periódicas entre os atores das instituições e órgãos que trabalham com a problemática" ${ }^{19}$ (p.82).

Apresentou-se, por fim, como proposta a ampliação e implantação de mais serviços nesta área de atuação, assim como a otimização de recursos humanos e materiais ${ }^{18,28}$. Para Costa et al. ${ }^{26}$ é necessário "fortalecer e ampliar a atuação dos Centros de Referência Sentinela (CREAS) e Conselhos Tutelares (CT), no que diz respeito ao atendimento em tempo integral, semanal e feriados, melhoria da infraestrutura dessas instâncias"26(p.571) para a consolidação da rede. Além de "incrementar a atuação de alguns setores, como o sistema de educação, defensoria e segurança pública, conselhos tutelares, CMDCA, mídia, com a rede de enfrentamento da violência”26(p.571). E a "capilarização do atendimento da atenção primária em saúde" ${ }^{\text {(p.873). }}$ 


\section{Discussões}

O Ministério da Saúde (MS) conceitua redes como "arranjos organizativos de ações e serviços de diferentes densidades tecnológicas, que, integradas por meio de sistemas de apoio técnico, logístico e de gestão, buscam garantir a integralidade do cuidado" ${ }^{30}$. Apesar de todos os artigos analisados anunciarem o enfoque no cuidado em rede, apenas seis deles definem a que rede se referem. Os conceitos se assemelham e se complementam, corroborando de certo modo a definição do MS, ao trazerem uma perspectiva de um trabalho comum e conjunto, de relações horizontais, em que as responsabilidades são compartilhadas entre os envolvidos no cuidado $^{2,18}$. Nas palavras de Faraj e Siqueira ${ }^{19}$, a rede se refere a "processos dinâmicos...", o que significa dizer que essa rede não está dada, ela se constrói a cada situação que surge.

Nesse sentido, pode-se considerar que a restrição da ideia de rede a um conjunto de serviços, como trazido pelos outros artigos, deixa de considerar questões importantes nessa discussão, como a problematização do próprio conceito teórico de redes de cuidados, nessa perspectiva da sua dinamicidade.

Segundo Carlson e Pinheiro ${ }^{31}$ é comum o conceito de rede estar atrelado à enumeração do rol de serviços de um determinado local, inclusos nisso os fluxos de encaminhamento, o que calcifica o discurso a uma "visão administrativa que, no máximo, aponta o que existe/inexiste de recursos no território"31 (p.106). Em detrimento disso, os autores apostam numa rede dinâmica, pautada "em práticas que produzam cuidado a partir da interrelação das diversas políticas públicas existentes" ${ }^{\prime 31}$ (p.106).

Certamente a existência dos vários serviços é condição necessária para constituição de rede, mas tal existência por si não garante uma comunicação efetiva e um cuidado de fato articulado; como trazido por Kinoshita ${ }^{32}$, a rede existe enquanto os indivíduos estão interagindo entre si de modo sincrônico e coordenado por um objetivo comum, de modo a permitir o surgimento de fenômenos que isoladamente seriam impossíveis de acontecer.

Com isso, para além da presença/ausência de dispositivos, entende-se o trabalho em rede como o estabelecimento de linhas de ação comum entre os diversos atores sociais existentes, o que ultrapassa a lógica do encaminhamento e do envio de relatório e afirma uma responsabilidade compartilhada entre os envolvidos ${ }^{31}$. Como anunciado por Habigzang et $\mathrm{al}^{3}{ }^{3}(\mathrm{p} .468)$, a rede consiste em um "conjunto de sistemas e de pessoas significativas (...) que compõem os relacionamentos existentes e percebidos pela criança" e adolescente.

Assim, como dito, parece limitada a definição de rede à descrição de sua composição por serviços formalmente designados como responsáveis pelo cuidado às crianças e adolescentes em situação de violência sexual, como as instituições de saúde, educação, assistência social e defesa dos direitos, como apresentada nos artigos. Entendese que tal nomeação pode acabar excluindo integrantes importantes, às vezes inimagináveis, que poderiam contribuir na composição desse cuidado em rede. Não se trata, portanto, de fixar lugares ordenados para as instituições envolvidas no cuidado a criança e adolescente em situação de violência sexual, e sim flexibilizar as possibilidades dos atores envolvidos e das ações caso a caso.

É inegável que algumas instituições são indispensáveis na constituição dessas redes de cuidados, como trazido pelos artigos: aquelas ligadas à educação, saúde, assistência social, justiça; mas faz-se importante não se restringir a esses dispositivos, entendendo que a rede poderá se ampliar de acordo com cada situação e vínculos de confianças desse adolescente em situação de violência sexual. Para além dos serviços, outras pessoas podem e devem compor essas redes de cuidados, considerando as múltiplas possibilidades de organização e necessidades presentes em cada situação. Nessa direção, comparece em um artigo $^{3}$ a família como membro potencialmente importante nessa composição da rede de apoio social as crianças e adolescentes em situação de violência sexual. A família consiste, possivelmente, na primeira rede social de qualquer pessoa, desse modo deve ser considerada nesse cuidado, para cuidar e ser cuidada.

Diante da complexidade da questão da violência, é importante que os serviços de saúde, assistência social, educação, segurança, defesa e proteção, e demais possíveis atores, como a família, "atuem de forma articulada e intersetorial, permitindo a flexibilidade e ampliação do fluxo em todas as dimensões possíveis do cuidado"30(p.76). Portanto, não se trata de enumerar uma lista taxativa dos serviços que compõem a rede nos casos de violência sexual de crianças e adolescentes, mas considerar que os serviços e os atores convocados podem variar de acordo com o caso.

Por outro lado, faz-se também importante essa nomeação dos serviços componentes desta 
rede, a fim de responsabilizar essas instituições pelo cuidado a essas crianças e adolescentes, correndo o risco, caso esses serviços não estejam identificados, deles se eximirem dessa responsabilidade frente à dificuldade de lidar com a situação de violência sexual contra esse público.

Em se tratando dos serviços de saúde disponíveis para o cuidado em rede às crianças e adolescentes em situação de violência sexual, os artigos analisados enfatizam os hospitais na atenção a esse público. Em revista do Conselho Nacional de Secretários de Saúde, em matéria sobre o papel do hospital na rede de atenção à saúde, problematiza-se a centralidade dessa instituição como uma questão histórica associada "à forma como o Brasil, ao longo dos anos, tratou a busca da solução para os problemas de saúde" ${ }^{33}$ (p.16), voltada a uma perspectiva curativista e biologizante. Nessa discussão, a revista argumenta sobre a necessidade de fortalecimento da Atenção Primária como principal estratégia de superação dessa lógica hospitalocêntrica e hierarquizada, para uma prática mais horizontalizada de cuidado, condizente com a perspectiva de construção de redes de apoio.

Entre os artigos analisados, apenas dois ${ }^{8,27}$ citam a Atenção Primária como importante no cuidado em rede à criança e adolescente em situação de violência sexual, o que destoa da própria orientação do $\mathrm{MS}^{30}$, que elenca a Atenção Primária, juntamente com a atenção especializada - urgência e emergência, os serviços de saúde mental e os serviços estratégicos de apoio à gestão, como importante componente das redes de cuidados e de proteção social às crianças e adolescentes em situação de violência.

A Atenção Primária tem como princípios: a universalidade, a acessibilidade, a coordenação e continuidade do cuidado, o vínculo (equipe-usuário), a integralidade, a responsabilização, a humanização, a equidade e a participação social; o que certamente aponta para o importante papel desse nível de atenção no cuidado a essa situação de violência. A proximidade geográfica da Atenção Primária com a população de dado território deve possibilitar o melhor acesso dessas pessoas ao cuidado que, sustentado pelo vínculo equipe-usuário, possa garantir uma atenção integral às crianças e aos adolescentes em situação de violência sexual. Há que se considerar também a responsabilidade desse nível de atenção na coordenação e continuidade do cuidado a esse público, uma vez que essas crianças e adolescentes, mesmo atendidos também por outros atores sociais, continuam a habitar aquele território onde a Unidade Básica de Saúde se faz presente.
Pode-se dizer assim que a Atenção Primária apresenta condições importantes de identificar sinais e sintomas de violências em crianças e adolescentes e de realizar ações de acolhimento, atendimento (diagnóstico, tratamento e cuidados), acompanhado da notificação dos casos e promoção à saúde desse público, no sentido de fomentar melhores condições de vida a partir da articulação intersetorial em rede.

Seguindo nessa discussão, em relação às práticas adotadas para o cuidado em rede, apenas dois dos artigos ${ }^{19,27}$ falam de como acontece esse trabalho em rede, por meio do "acolhimento" para "coleta e análise de dados", "encaminhamentos" necessários e envio de relatórios. Nesse sentido, o entendimento de acolhimento parece se aproximar mais de uma "triagem administrativa, ou um bom encaminhamento para serviços especializados" ${ }^{34}$ (p.124), que propriamente uma "postura ética que implica na escuta do usuário em suas queixas, no reconhecimento do seu protagonismo no processo de saúde e adoecimento, e na responsabilização pela resolução, com ativação de redes de compartilhamento de saberes" ${ }^{35}$.

Isso não significa em absoluto que a "coleta e análise de dados" não sejam importantes no cuidado, mas se torna imprescindível nesse contexto de violência que o acolhimento seja tomado por todos os profissionais como uma atitude cotidiana de escuta qualificada do sofrimento do outro, colocando-se disponível a construção conjunta de alternativas saudáveis de estar na vida.

Com isso, coloca-se em questão também a prática de encaminhamento dentro dessa rede, que, em geral, ao contrário de gerar interlocução das ações em saúde para a integralidade do cuidado, reforça uma perspectiva de transferência de responsabilidade e um modo de relação baseada na hierarquia de poder/saber entre quem encaminha e quem recebe ${ }^{36}$. Sem contar a possível fragmentação suscitada por essa lógica de encaminhamento, em que cabe a cada um a sua parte. Faz-se presente assim, possivelmente, uma comunicação não fluida, que marca uma rede fragmentada, ilustrada pela descontinuidade no cuidado $^{17}$. Nessa direção, Santos et al. ${ }^{29}$ trazem inclusive essa restrição ao encaminhamento como uma dificuldade de efetivação do trabalho em rede pela ideia que se tem, a partir dessa prática, de resolução dos casos. Os autores argumentam que tal prática gera "repetições de intervenções e avaliações e a super-exposição da família, promovendo o seu esgotamento e esgotando as possibilidades de resultados" 29 (p.85).

Isso porque a grande dificuldade para a consolidação das redes de cuidados às crianças $\mathrm{e}$ 
adolescentes em situação de violência sexual está justamente na falta de comunicação entre os serviços, atores e setores dessa rede, como apontado pelos artigos. Nesse sentido, advoga-se por se investir nessa comunicação entre esses atores envolvidos nesse cuidado para a efetivação de uma rede pautada na co-responsabilização. Uma comunicação efetiva engloba troca de conhecimentos nos serviços e entre estes, além de contatos contínuos $^{37}$.

Nesse contexto de discussão, vale destacar a falta de clareza dos artigos em relação ao modo de se concretizar as propostas trazidas por eles. Cinco dos artigos analisados trazem como proposta para um cuidado em rede a capacitação dos profissionais. É notória a imprescindibilidade de formação dos profissionais para esse cuidado às crianças e adolescentes em situação de violência sexual, principalmente considerando os desafios no lidar com essa situação e sua necessidade de articulação intersetorial. Essa formação, representada pela perspectiva também da Educação Permanente, é trazida pelo $\mathrm{MS}^{30}$ como passos para estruturação da própria rede.

Sendo assim, vale acrescentar como proposta de ação para a construção de um cuidado em rede a essas crianças e adolescentes, para além de capacitações em serviços, os pressupostos da Educação Permanente. A capacitação é entendida como ações planejadas com objetivos previamente estabelecidos e com a finalidade de atualização sobre determinados assuntos, notadamente quando há lacunas em relação a determinado conhecimento ${ }^{38}$. Já a Educação Permanente é conceituada como aprendizagem no trabalho, em que "o aprender e o ensinar se incorporam ao cotidiano das organizações e ao trabalho"38(p.20). Assim, baseia-se na possibilidade de transformar as práticas profissionais por meio das vivências cotidianas, considerando conhecimentos e experiências que as pessoas já possuem para uma mudança institucional ${ }^{38}$.

Em pesquisa realizada por Trabbold et al. ${ }^{7}$, a maioria dos profissionais entrevistados numa Unidade de Saúde da Família se referiram aos adolescentes como aqueles que dificilmente têm contato com o serviço, fato interpretado como resistência desse público em procurar o serviço de saúde. Por outro lado, as autoras invertem essa ideia e dizem de um serviço de saúde que tem dificuldade de acolher esse adolescente, por um despreparo e insegurança dos profissionais em lidarem com o adolescente e com a complexidade da violência sexual ${ }^{7}$. Dessa forma, as autoras evidenciam o hiato no enfoque da adolescência no setor saúde de forma geral e, notadamente, da questão da violência. Lacuna essa que parece se estender também para o campo das produções científicas nacionais, daí a importância de se investir sempre na formação dos diversos atores sociais para o cuidado a esse público em situação de violência sexual.

\section{Considerações finais}

Este trabalho objetivou levantar e analisar as produções científicas nacionais sobre as redes de cuidados aos adolescentes em situação de violência sexual. A partir daí foi possível apreender que para além das dificuldades relativas às situações de violência sexual contra crianças e adolescentes, são grandes os desafios de constituição das redes de cuidados. Tanto que os artigos, apesar de anunciarem o enfoque nas redes de cuidados às crianças e adolescentes em situação de violência sexual, em sua maioria não apresentam o entendimento de rede e o modo como ela funciona, no que diz respeito às práticas cotidianas na direção de um cuidado mais integral a esse público. Entende-se que essa não conceituação teórica de rede pode associar-se às dificuldades práticas de consolidação dessas redes de cuidados pretendidas. Nesse sentido, marca-se a necessidade de mais estudos que apresentem essa rede em funcionamento, de modo a contribuir para outras práticas em rede no país e ampliação teórica sobre a temática em questão.

É grande a dificuldade em encontrar discussões teóricas sobre as redes de cuidados aos adolescentes em situação de violência sexual, tanto que foi preciso incluir artigos que tinham como público alvo também as crianças para que esse estudo acontecesse. Assim, diante da relevância do tema, considerado grave problema de saúde pública, e do desfalque das produções que lidam mais especificamente com a questão da adolescência nos casos das redes de cuidados às situações de violência sexual, faz-se necessário investir em estudos na área.

Nessa linha de discussão sobre a ampliação dos debates sobre a temática proposta por esta pesquisa, chama atenção ainda o fato de poucos artigos abordarem a família e o território, também na figura da Atenção Primária, como componentes possíveis e importantes na constituição dessa rede, assim como a abertura para a composição com outros atores sociais.

Nesse contexto, é possível afirmar que para além de capacitações para os profissionais envol- 
vidos nesse cuidado, como trazido pelos artigos, faz-se necessário investir na efetivação da Educação Permanente, por sua proposta de transformação dos profissionais em sujeitos, agentes de mudanças, colocando-os no centro do processo de ensino/aprendizagem. A partir daí a expectativa é que se possam operar espaços de acolhimento - do modo como discutido nesse texto - que promovam a reinvenção da vida pela saúde do público.

\section{Colaboradores}

GB Broseguini trabalhou na concepção, pesquisa e redação final e A Iglesias trabalhou na concepção, redação e revisão crítica do trabalho.

\section{Referências}

1. Kappel VB, Gontijo DT, Iwamoto HH, Isobe RMR. Enfrentamento da violência sexual infanto-juvenil na perspectiva dos participantes de um curso de formação. Cogitare Enferm 2012; 17(2):217-223.

2. Deslandes SF, Campos DS. A ótica dos conselheiros tutelares sobre a ação da rede para a garantia da proteção integral a crianças e adolescentes em situação de violência sexual. Cien Saude Colet 2015; 20(7):2173-2182.

3. Habigzang LF, Ramos MS, Koller SH. A revelação de abuso sexual: as medidas adotadas pela rede de apoio. Psic Teor Pesq 2011; 27(4):467-473.

4. Brasil. Comitê Nacional de Enfrentamento à Violência Sexual contra Crianças e Adolescentes. Plano $\mathrm{Na}$ cional de Enfrentamento à Violência Sexual Contra a Criança e o Adolescente. Brasília: Conanda, PNEVESCA, ECPAT Brasil, UNICEF, CECRIA; 2013.

5. Fundo das Nações Unidas para a Infância (UNICEF). Situação da adolescência brasileira. $O$ direito de ser adolescente: oportunidade para reduzir vulnerabilidades e superar desigualdades. Brasília: UNICEF; 2011.

6. De Antoni C, Yunes MAM, Habigzang L, Koller SH. Abuso sexual extrafamiliar: percepções das mães de vítimas. Estud Psicol (Campinas) 2011; 28(1):97-106.

7. Trabbold VLM, Caleiro RCL, Cunha, CF, Guerra AMC. Concepções sobre adolescentes em situação de violência sexual. Psicol Soc 2016; 28(1):74-83.

8. Deslandes SF, Vieira LJES, Cavalcanti LF, Silva RM. Atendimento à saúde de crianças e adolescentes em situação de violência sexual, em quatro capitais brasileiras. Interface (Botucatu) 2016; 20(59):865-877.

9. Brasil. Lei no 8.069, de 13 de julho de 1990. Dispõe sobre o Estatuto da Criança e do Adolescente e dá outras providências. Diário Oficial da União 1990; 16 jul..

10. Silva LLT, Vecchia BP, Braga PP. Adolescer em pessoas com doenças crônicas: uma análise compreensiva. Rev Baiana Enferm 2016; 30(2):1-9. 
11. Brasil. Ministério da Saúde (MS). Caderneta de Saúde do Adolescente (MENINA). Brasília: MS; 2013.

12. Rassial JJ. O adolescente e o Psicanalista. Rio de Janeiro: Companhia de Freud; 1999.

13. Lo Bianco AC, Nicacio E. O adolescente e o encontro com os impasses do sexual. Cad Psicanál 2015; 37(33):71-84.

14. Menandro MCS, Trindade ZA, Almeida AMO. Representações sociais da adolescência/juventude a partir de textos jornalísticos (1968-1974 e 1996-2002). Arq Bras Psicol 2003; 55(1):42-55.

15. Paixão ACW, Deslandes SF. Abuso sexual infanto juvenil: ações municipais da Saúde para a garantia do atendimento. Cien Saude Colet 2011; 16(10):41894198.

16. Santos BR, Ippolito R. Guia escolar: métodos para identificação de sinais de abuso e exploração sexual de crianças e adolescentes. Brasília: Secretaria Especial dos Direitos Humanos e Ministério da Educação; 2011.

17. Castells M. A sociedade em rede. São Paulo: Paz e Terra; 2000.

18. Rodrigues SG, Constâncio TB, Neves MGC. Rede contra Violência Sexual no DF: uma representatividade da saúde e da educação na adolescência. Com Cien Saude 2011; 22(4):343-352.

19. Faraj SP, Siqueira AC. O atendimento e a rede de proteção da criança e do adolescente vítima de violência sexual na perspectiva dos profissionais do CREAS. Barbarói 2012; 37:67-87.

20. Habigzang L, Caminha RM. Abuso Sexual contra crianças e adolescentes: conceituação e intervenção clínica. São Paulo: Casa do Psicólogo; 2004.

21. Gava LL, Dell'Aglio DD. Percepções de psicólogos sobre a perícia nos Institutos MédicoLegais do Brasil. Estud Psicol (Natal) 2013; 18(4):609-661.

22. Cordeiro AM, Oliveira GM, Renteria JM, Guimarães CA. Revisão sistemática: uma revisão narrativa. Rev Col Bras Cir 2007; 34(6):428-431.

23. Mendes KDS, Silveira RCCP, Galvão CM. Revisão Integrativa: método de pesquisa para a incorporação de evidências na saúde e na enfermagem. Texto Contexto Enferm 2008; 17(4):758-764.

24. Zoltowski APC, Costa AB, Teixeira MAP, Koller SH. Qualidade metodológica das revisões sistemáticas em periódicos de psicologia brasileiros. Psic Teor Pesq 2014; 30(1):97-104.

25. Bardin L. Análise de conteúdo. Lisboa: Ed. 70; 1988.

26. Costa MCO, Carvalho Rcde, Santana MAO, SilvaLMS, Silva MR. Avaliação do Programa Nacional de Ações Integradas e Referenciais (PAIR) para o enfrentamento da violência sexual contra crianças e adolescentes, em Feira de Santana, Bahia. Cien Saude Colet 2010; 15(2):563-574.

27. Espindola GA, Batista V. Abuso sexual infanto-juvenil: a atuação do programa sentinela na cidade de Blumenau/SC. Psicol Cien Prof 2013; 33(3):596-611.
28. Paixão ACW, Deslandes SF. Análise das Políticas Públicas de Enfrentamento da Violência Sexual Infantojuvenil. Saúde Soc 2010; 19(1):114-126.

29. Santos VA, Costa LF, Silva AX. As medidas protetivas na perspectiva de famílias em situação de violência sexual. PSICO 2011; 42(1):77-86.

30. Brasil. Ministério da Saúde (MS). Linha de Cuidado para a Atenção Integral à Saúde de Crianças, Adolescentes e suas Famílias em Situação de Violências: Orientação para gestores e profissionais de saúde. Brasília: MS; 2010.

31. Carlson ACR, Pinheiro LS. Práticas intersetoriais: novos desafios postos aos psicólogos na atual política de assistência social. In: Cruz LR, Rodrigues L, Guareschi NMF. Interlocuções entre a Psicologia e a Política $\mathrm{Na}$ cional de Assistência Social. Rio Grande do Sul: Edunisc; 2013.

32. Kinoshita RT. Crise e urgência. Vídeo-aula ministrada no curso Crise e Urgência em Saúde Mental realizado na Universidade Federal de Santa Catarina (UFSC); 2014.

33. Conselho Nacional dos Secretários de Saúde. Consensus: Revista do Conselho Nacional de Secretários de Saúde. Brasília: Editora Terra Brasilis; 2014.

34. Motta BFB, Perucchi J, Filgueiras MST. O acolhimento em Saúde no Brasil: uma revisão sistemática de literatura sobre o tema. Rev SBPH 2014; 17(1):121-139.

35. Brasil. Ministério da Saúde (MS). Politica Nacional de Humanização. Brasília: MS; 2008.

36. Iglesias A. O Matriciamento em Saúde Mental sob vários olhares [tese]. Vitória: Universidade Federal do Espírito Santo; 2015

37. Gomes LB, Bueno AX. A educação permanente no cotidiano do trabalho em saúde. In: Gomes LB, Barbosa MG, Ferla AA, organizadores. A educação permanente em saúde e as redes colaborativas: conexões para a produção de saberes e práticas. Porto Alegre: Editora Rede Unida; 2016.

38. Brasil. Ministério da Saúde (MS), Política Nacional de Educação Permanente em Saúde. Brasília: MS; 2009.
Artigo apresentado em 03/03/2018

Aprovado em 15/04/2019

Versão final apresentada em 17/04/2019 